The improvements in the art must come from the men equipped with chemical knowledge. I have been unable to discover a mechanical pracess that will fully separate encrusting salts from water inexpensively. Closed heaters separate a certain percentage of carbonates depending on the temperature, pressure and relative flow of the water. I

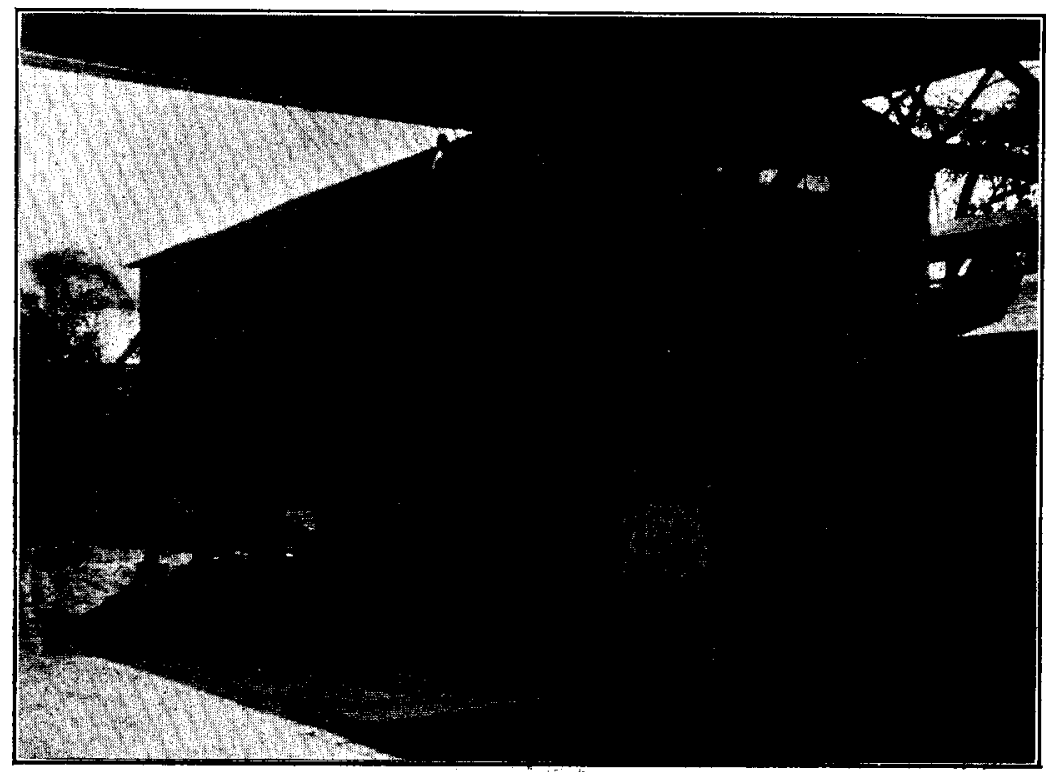

Fig. 9.-Housing for 2000 H. P. plant, $12^{\prime} \times 40^{\prime}$.

have found a removal of from 25 per cent. to 75 per cent. of these salts. High temperature and pressure heaters made to remove gypsum fail fully to do so. Analyses of treated water from such heaters have not shown more than 50 per cent. to 75 per cent. removal of sulphates. Moreover, the process is expensive both from the standpoint of steam used and labor required to remove the trays encrusted with heavy scale.

A considerable percentage of the soft returned water from a plant can be saved and used again. Chemical engineers need to thoroughly investigate the removal of oil from water. It seems possible to perfect a device provided with a chemical bath that will effect complete removal of oil. We need a thorough investigation of chemicals or processes that shall result in the complete removal of sulphates from water. Barium salts are considered dangerous by concerns using live steam for food purposes. Whether, when foaming occurs, such salts are dangerous is yet to be determined, but it seems entirely possible that the prejudices are fully founded. No cheaper material than lime can probably be found for the removal of carbonates.

\section{HEAT TREATMENT OF HIGH-SPEED TOOLS. ${ }^{1}$}

By C. P. BERG, M. W. S. E.

Received November 1, 1910.

The experiments described in this paper were undertaken in order to obtain the relation between temperature in tempering and the life of tools to a greater degree of exactness than heretofore known to the writer.

The perfection of the electric furnace for high temperatures and development of same into dimensions for such practical purposes as heat treatment of metal-cutting tools, in connection with the electric pyrometer for measuring these high temperatures, has made possible such investigations as stated above.

The wr ter will confine himself conclusively to the attempt of solving the problem as it concerns the effect of various temperatures upon the life of high-speed tools, or the comparative values of the same.

Although the carbon steels are of decidedly earlier origin and have been experimented upon by several investigators, it is the hope of the writer to attempt an addition to the present available information in the near future.

Most notable of recent scientific work in this line is the paper presented by Mr. George W. Sargent, Ph.D., at the meeting of the Franklin Institute, June 3, 1909: "Some remarks upon the critical points of steel, their method of determination, and the value of same," in which he records a series of experiments made at the Carpenter Steel Works.

While the heat treatments and various tests described in his paper were conducted in a thoroughly scientific manner, Mr. Sargent failed to show the value of his investigations on the life of metal-cutting tools.

Fully appreciating the value of specialists for the various tests required to complete this work, the writer has been fortunate in being associated with, and assisted by, professional experts during the entire experimenting period, each one carrying on his special part of the investigation.

The writer would particularly mention Messrs. W. C. Post, A. D. de Pierrefeu and J. H. Critchett, of the Chicago Metallurgical Laboratory, in connection with the metallurgical examination by photomicrographs, Mr. James Lowrie, Ph.D., with the hardness test, and Mr. W. V. Young, of the Hoskins Mfg. Co. $\mathrm{He}$ would also acknowledge his indebtedness to the Hoskins Mfg." Co. for enabling him to carry on the heat treatments at their Chicago demonstrating

1 Copyright, 1910, by C. P. Berg. Read before the Western Society of Engineers, June 15,1910. All rights of reproduction reserved as to text, illustrations and diagrams. 
plant, and the Link-Belt Company, at which shops the cutting tests were performed.

To recapitulate: The writer's work may be said to consist of :

A. Establishing a guide as to how rapidly the steel should be heated under the high heat treatment by a heat absorption test.

B. Determining at which degree of temperature in the heat treatment, the maximum cutting efficiency occurs for a steel of a certain chemical composition.

C. Giving reasons for the relations found by these tests by metallurgical examinations and to illustrate the same by photomicrographs.

Steels Used in Test.-Four prominent high-speed steels were selected to be experimented upon. These steels were marked $A, B, C$, and $D$, and these marks will be retained in referring to the four series of specimens undergoing the various tests.

The chemical analyses of these steels are as shown in Table I:

\begin{tabular}{|c|c|c|c|c|}
\hline \multicolumn{5}{|c|}{ Figures are percentages. } \\
\hline & A. & B. & c. & D. \\
\hline Carbon, C......... & 0.70 & 0.56 & 0.74 & 0.67 \\
\hline Silicon, Si........... & 0.211 & 0.248 & 0.262 & 0.278 \\
\hline Sulphur, s . . . . . . & 0.016 & 0.035 & 0.016 & 0.010 \\
\hline Phosphorus, P.... & 0.010 & 0.012 & 0.016 & 0.015 \\
\hline Manganese, Mn ... & 0.27 & 0.20 & 0.21 & 0.22 \\
\hline Chromium, Cr..... & 4.76 & 5.54 & 5.80 & 3.30 \\
\hline Tungsten, $W \ldots \ldots \ldots$ & 15.15 & 8.45 & 10.94 & 15.37 \\
\hline Nitrogen, $N \ldots \ldots \ldots \ldots$ & 0.005 & 0.005 & 0.004 & 0.015 \\
\hline
\end{tabular}

Tools Used in Test.-In order to eliminate the effect of forging upon the steels to be tested, straight tools for boring or inside turning, ground to shape and to standard angles in a grinder, were decided upon.

Steel bars of $3 / 8$ by $I^{1} / 2$ in. size were cut off from the four previously mentioned steels, to be made into tools for roughing cuts in boring cylinders to $4 \frac{1}{2}$ in. diameter. The tools were treated and ground with a cutting edge on both ends and to cutting angles as shown in the accompanying sketch (Fig. I).

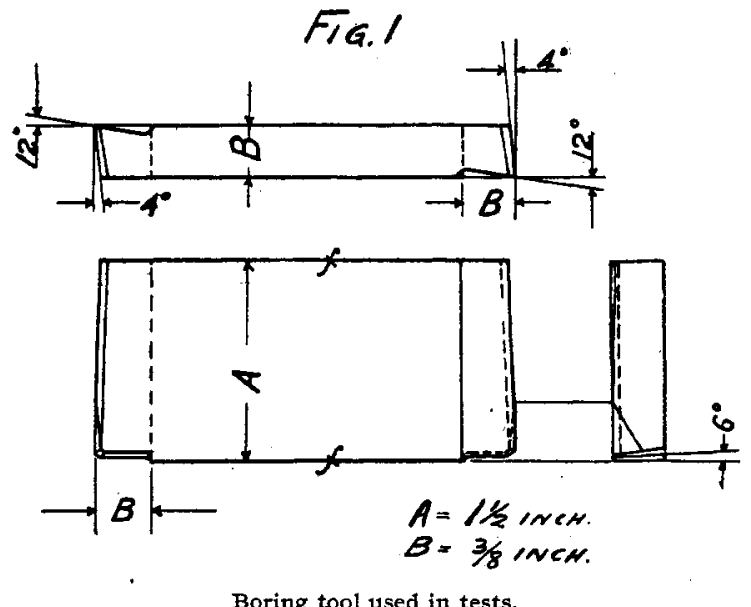

Specimens Used for Physical Tests.-Cylinders made from cast-iron of a chemical composition producing exceptionally hard castings were provided for this test.

In order to insure equality, the greatest care was taken in preparing the molds for these castings, and all were poured from the same heat.

In view of the fact that the life of a tool decreases with the increase of combined carbon in the castings on which it is used, and again that the amount of combined carbon is dependent upon the rapidity with which the cast-iron is cooled after pouring it into the mold, it became necessary to find some method by which these castings could be cooled in the same length of time.

The molds were therefore specially arranged for this purpose, and eight minutes after the iron was poured the cores were removed and the castings cooled in water. This gave the castings as nearly as possible the same amount of combined carbon.

Dimensions of the cylinders were as follows: Outside diameter, 8 inches; length, 8 inches; and diameter of core, 4 inches; leaving $1 / 2$ inch of metal to be removed by the double end tools to be tested, or, in other words, providing for $1 / 4$-inch depth of cut for each end of the tool.

The thickness of metal or walls of the cylinders being 2 inches, the castings were inspected for soundness and then considered if of the quality for the test or condemned.

Heat Treatment of the Tools.-The temperatures used in the heat treatment of, tools have heretofore generally been measured in practice by the terms: cherry-red, bright yellow, white, etc. These measurements of heat were probably as correct as any other in connection with the old-time method of tempering tools in the blacksmith forge, where no accurate control of the heat could be obtained.

Admitting that there are experts in this line, who are able to guess temperatures very closely by the color of the heated steel, the writer has heard differences of opinions, when the limit line was to be drawn between white and bright yellow, etc.

With the modern electric furnace, its perfect control, evenly distributed heat, reducing atmosphere preventing burning of the steel, and the thermoelectric pyrometer for measuring temperatures, the science of treating metal-cutting tools has taken a long step forward.

The instruments as used for the experimental tools are shown in the accompanying illustration (Fig. 2) from a photograph. To the left can be seen the muffle furnace used for preheating the steel slowly up to $1400^{\circ} \mathrm{F}$., prior to transferring it to the tube furnace, seen to the right in the picture, there to be subjected to the high heat treatment.

The muffle furnace, to the left, is of the wire resistance type constructed for temperatures up to $1800^{\circ} \mathrm{F}$.

The tube chamber design of furnace, to the right, 
where the experimental tools were subjected to the high-heat treatment, is constructed for temperatures up to $2600^{\circ} \mathrm{F}$.

The current for both of these furnaces is controlled on the switchboard shown in the center of Kig. 2 . allowed for the heat to penetrate thoroughly to the center of the tool, which otherwise would be in danger of cracking.

To do this it is necessary to know the length of time required by the tool under treatment to absorb

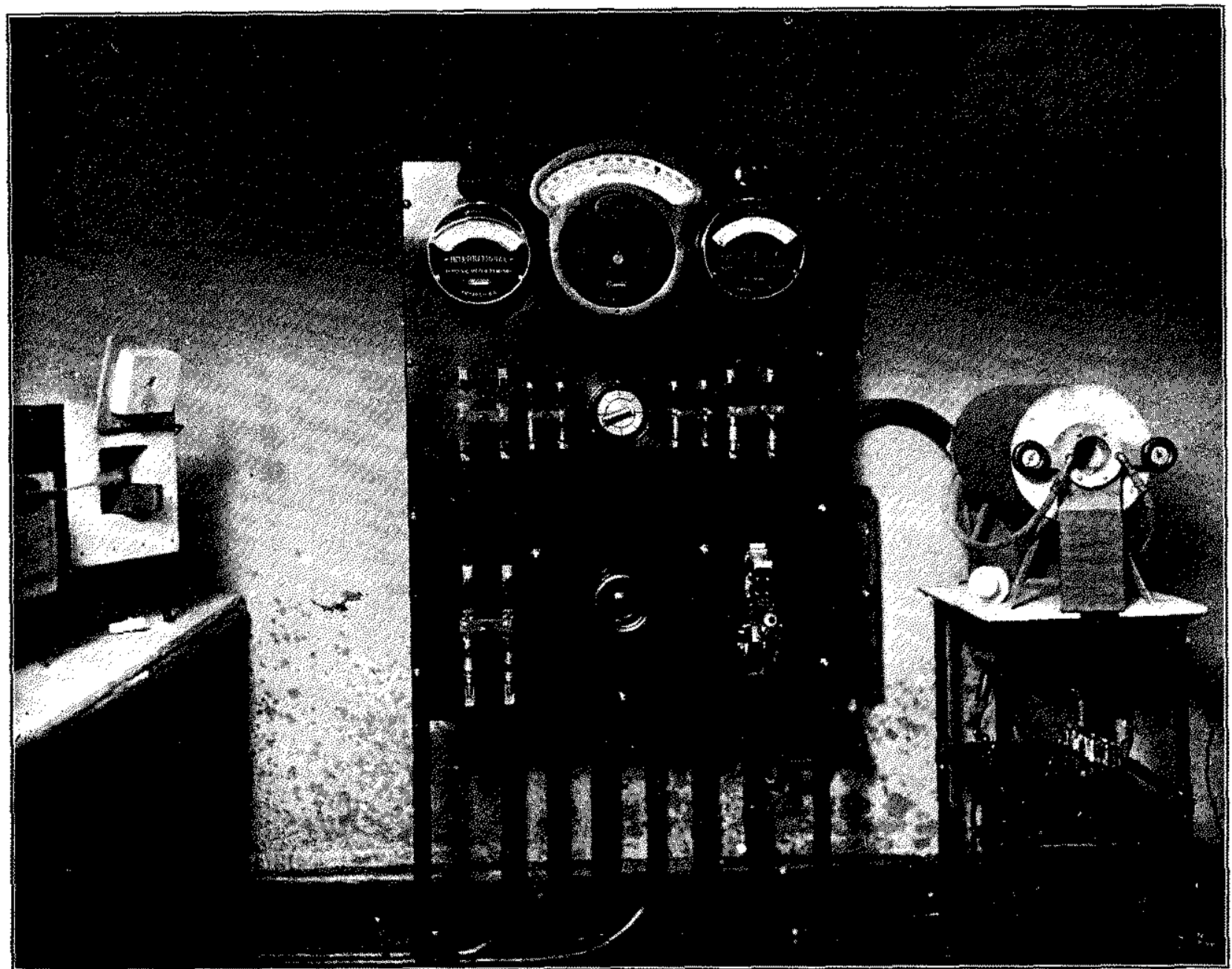

Flectric theating furtaces and switchboard.

The switchboard also carries the thermoelectric pyrometer, which is connected with the thermo-couples by the switch in the center of the board, this rendering possible the reading of temperatures in several furnaces on this one instrument by turning the switch, the contact points of the switch being numbered to avoid confusion. A wiring diagram of the pyrometer and selective switch is shown in Fig. 3 .

To insure accuracy the thermo-couples used were calibrated before and after the readings made on the temperatures of the test specimens. The calibrating consisted in taking a reading on water at the boiling point $\left(212^{\circ} \mathrm{F}.\right)$, on aluminum at the melting point $\left(12 \times 5^{\circ} \mathrm{F}\right)$, and on copper at the melting point (I949 $9^{\circ}$ F.).

In giving high-speed tools the high-heat treatment, the temperature should be raised rapidly to the desired degree for quenching, but enough time should be the heat to which it is subjected. In order to ascertain this for a guide in treating the experimental tools, the heat absorption test was made, from which the results are shown by the diagram in Fig. 4 .

Four pieces of steel of equal size, $3 / 8$ in. by $\mathrm{I}^{1} / 2$ in. by $I^{1 / 2}$ in., one from each end of $A, B, C$, and $D$, were prepared with a hole to receive the end of the thermocouple, as shown in Fig. 5 .

The furnace was run up to $2200^{\circ} \mathrm{F}$. and kept at this temperature. The test pieces were placed in the furnace individually and time observations were taken on the increasing temperature of the steel.

Noting the uniformity of the curves in the diagram, Fig. 4, it will be seen that the molecular change in the steel up to $2200^{\circ} \mathrm{F}$. did not at any point disturb the evenly increasing temperature of the specimen. As will appear later, it was found that some of these steels are treated with the best results at 
$2150^{\circ} \mathrm{F}$. The molecular change evidently is not violent enough and quick enough to stop the increase of temperature in the steel, at least it could not be observed by the instruments used.

From other tests made on heat absorption with various sizes of steel, it appears that the time for the absorption of heat increases very nearly in proportion to the thickness of the steel. Thus, a piece of steel $3 / 4$ in. thick requires twice as long a time as is shown by the diagram in Fig. 4, which would be 6.6 minutes for a temperature of $2150^{\circ} \mathrm{F}$., for any one of the $A, B, C$ and $D$ steels.

Plate I shows fractures of specimens from Series $\mathrm{A}$, which have been heated to $215^{\circ} \mathrm{F}$. but which were

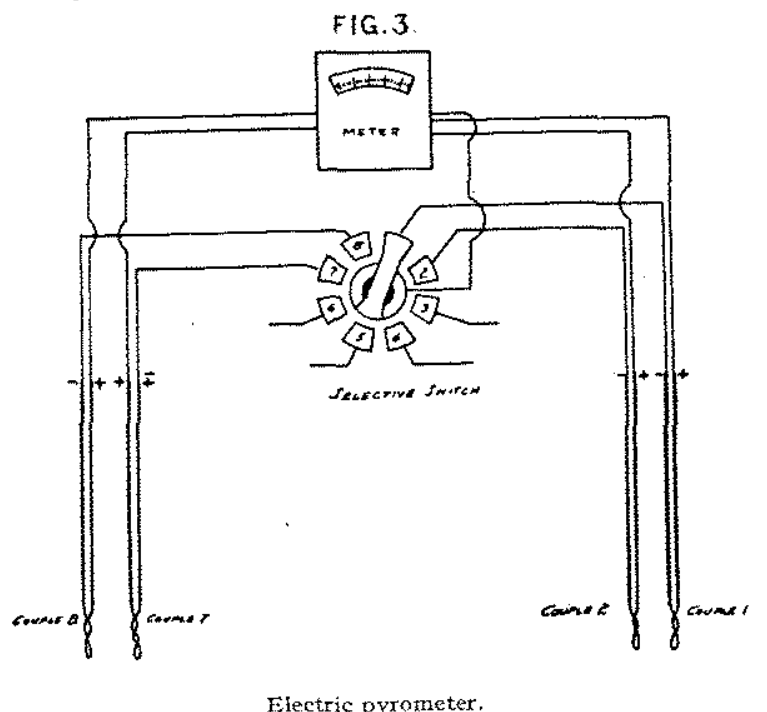

left in the furnace a certain length of time after reaching this temperature before quenching in oil at $100^{\circ}$ $F$. Comparing these fractures with the ones from the experimental tools and the results from the physical tests of the latter, they strongly indicate the necessity of careful observation in the matter of time for the tool to remain in the furnace to become thoroughly and uniformly heated.

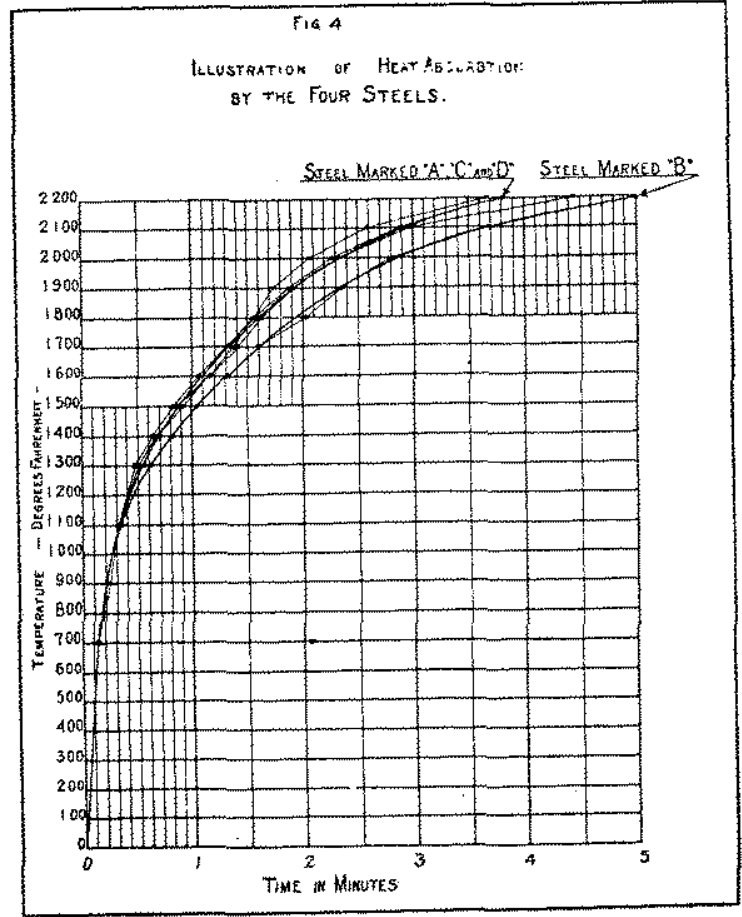

The heat absorption of steels.

A hardness test of these specimens performed with a scleroscope gave the results shown in the following table:

FIG.5

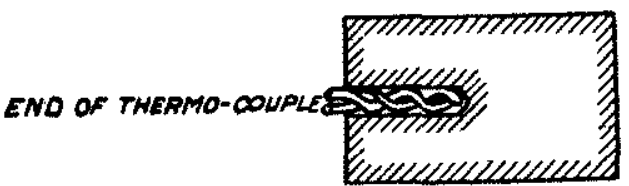

Fractures from specimens of Seties A heated to $2150^{\circ}$ Fahr. and the length of time for the specimens to remain in the furnace varied. Specimens quenched in oil at $100^{\circ}$ Fahr.

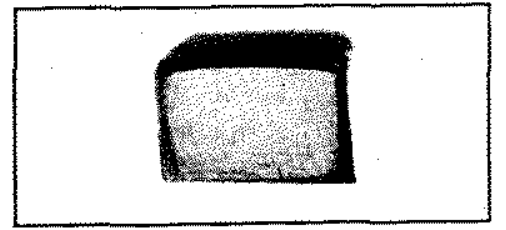

1-Left in furnace $2 \mathrm{~min}$. before quenching.

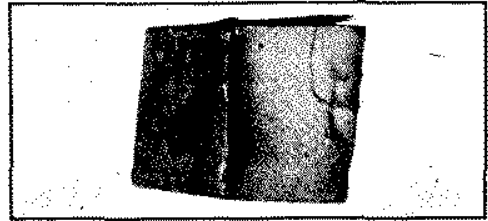

4-Left in furnace 8 min. befoce quenching.

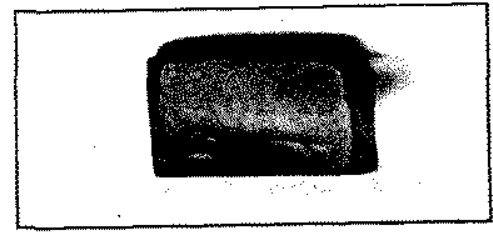

2-I.eft in furnace $4 \mathrm{~min}$. before quencling.

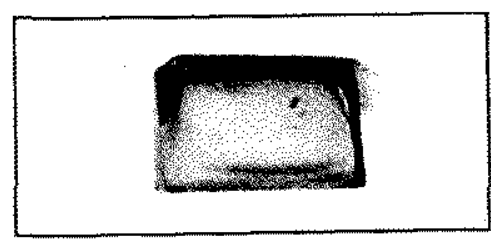

$5-$ Left in furnace $10 \mathrm{~min}$, before quenching.

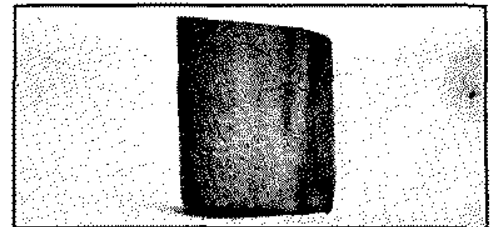

3 -Left in furnace 6 min. befott quenching.

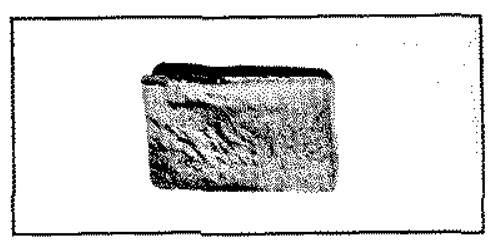

$6-$ Left in furnace 12 min. before quenching. 


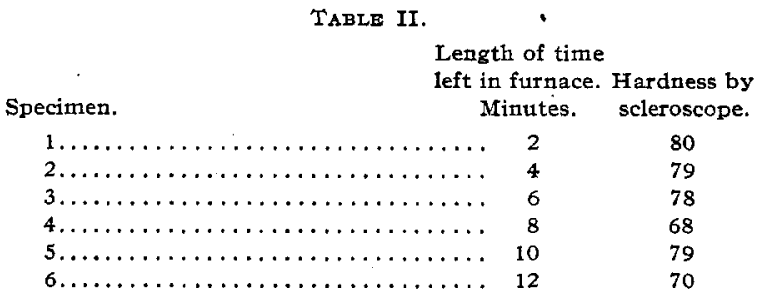

Based upon the above results, the heat treatment of the experimental tools was undertaken.

The specimens were marked, preheated to $1400^{\circ}$ F. and from this temperature heated to the various degrees of high heat, as shown in Table III. At the temperatures indicated in the table, the specimens. were quenched in oil, which was kept constant at $100^{\circ} \mathrm{F}$.

For convenient comparison, the results of hardness tests with the scleroscope upon the treated specimen have been shown in Table III:

\begin{tabular}{|c|c|c|c|}
\hline & AABLE & & \\
\hline & 1 & 1850 & 78 \\
\hline & 2 & 1900 & 81 \\
\hline & 3 & 1950 & 76 \\
\hline & 4 & 2000 & 78 \\
\hline & 5 & 2050 & 81 \\
\hline A................ & 6 & 2100 & 82 \\
\hline & 7 & 2150 & 83 \\
\hline & 8 & 2200 & 81 \\
\hline : & 9 & 2250 & 77 \\
\hline & 10 & 2250 & 77 \\
\hline & 0 & 2300 & 74 \\
\hline - & 11 & 1850 & 78 \\
\hline & 12 & 1900 & 74 \\
\hline & 13 & 1950 & 75 \\
\hline & 14 & 2000 & 77 \\
\hline & 15 & 2050 & 83 \\
\hline B............................ & 16 & 2100 & 83 \\
\hline & 17 & 2150 & 82 \\
\hline & 18 & 2200 & 79 \\
\hline & 19 & 2250 & 78 \\
\hline & 20 & 1750 & 68 \\
\hline ( & 21 & 1950 & 78 \\
\hline & 22 & 2050 & 80 \\
\hline & 23 & 2100 & 80 \\
\hline & 24 & 2150 & 83 \\
\hline & 25 & 2200 & 80 \\
\hline 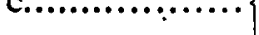 & 26 & 2250 & .75 \\
\hline & 27 & 2300 & 73 \\
\hline & 28 & 2350 & \\
\hline & 29 & 2325 & 71 \\
\hline & 30 & 2350 & 68 \\
\hline & 31 & 1950 & 70 \\
\hline & 32 & 2050 & 75 \\
\hline . & 33 & 2100 & 76 \\
\hline & 34 & 2150 & 81 \\
\hline & 35 & 2200 & 79 \\
\hline D... & 36 & 2250 & 83 \\
\hline & 37 & 2300 & 86 \\
\hline . & 38 & 2350 & 86 \\
\hline & 39 & 2300 & 86 \\
\hline & 40 & 2400 & 84 \\
\hline
\end{tabular}

Specimen 0 , of Series A, softened and caved in on one side.

Specimen 28, of Series C, softened so the free end (not supported by the tongs) tore off in removing it from the furnace. Specimen 30 was taken to replace the broken one, and special precautions were made for its removal from the furnace, and it was quenched without mishaps.
The specimens receiving the maximum heat all fused at the ends without exception, and some were, as previously stated, considerably softened.

In order to get the reading of temperature of the steel itself, a wire loop (wire $3 / 64$ in. diam.) was put around one end of two specimens, which were to receive an equal amount of heat. The loop was made loose enough to permit the moving apart of the two free ends of the specimens. A wedge-formed space was obtained between them, in which the end of the thermo-couple was held firmly, yet from which it could be easily removed.

Physical Tests. - The life or durability of these tools, treated in the previously described manner, appears to vary a good deal. Being ground into tools as described in preceding paragraph, and shown in Fig. I, the specimens were put to work under equal conditions on the casting described in several preceding paragraphs.

A 34-in. vertical boring mill was selected for the test, in order that the chips should clear away from the tool easily. The ends of the cylinders were faced, to eliminate the scraping of this scale by the experimental tools.

The results from the test run on the specimens from Series A are plotted in the diagram (Fig. 6).

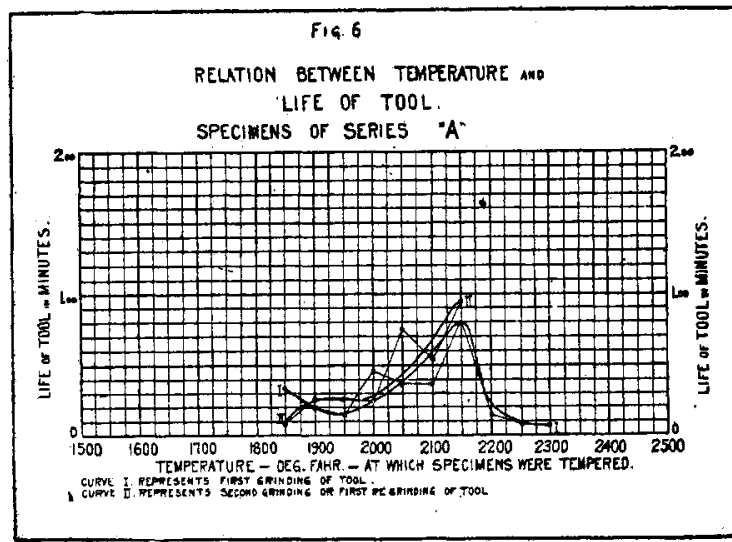

"A" steels-temperature and life.

It should be noted that the specimens quenched a a temperature above $2{ }^{\prime} 5^{\circ} \mathrm{F}$. failed almost immediately and broke.

The second curve (II), which represents the second grinding of the tool, shows a slight increase in durability. This indicates the effect a second heat treatment (drawing the temper of the tool after the highheat treatment) would have upon the tool, which effect can be gotien as readily by running the tool at high-cutting speeds until it fails, and have it reground, as by drawing the temper in the furnace. However, this method is less accurate, as there is no means of determining the heat thus developed under the cutting action, at the present time.

The cutting speed, 80 feet per minute, the thickness 
of the shaving or feed per revolution, 0.0339 inch, and depth of cut, $1 / 4$ inch at each end of the tool, were kept constant for all specimens and for both grindings.

Results from the test run on the specimens of series $\mathrm{B}$ are plotted in diagram (Fig. 7).

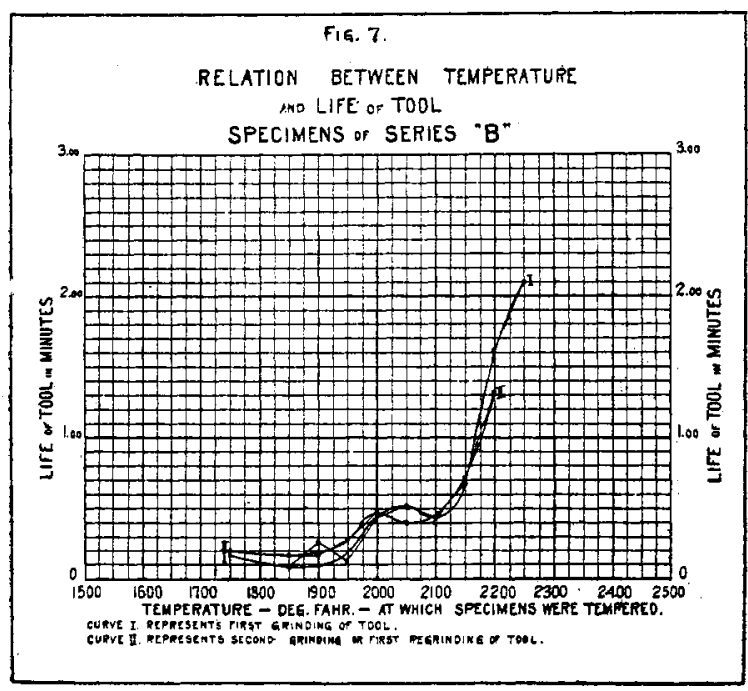

" $B$ " steeis--temperature and hife.

The curves here do not present a great deal of uniformity at the low temperatures, but improve and become more distinct as the temperature increases.

The specimen receiving the highest heat showed the maximum durability, but it failed vey suddenly and broke into several pieces. The fractures gave evidence of brittleness.

Practically no difference in durability appears between the first and second grinding of the tool.

The cutting speed, 80 feet per minute, the thickness of the shaving or feed per revolution, 0.0339 inch, and depth of cut, $1 / 4$ inch at each end of the tool, were kept constant for all specimens and for both grindings.

The results from the tests run on the specimens of series $\mathrm{C}$ are found plotted in the diagram (Fig. 8).

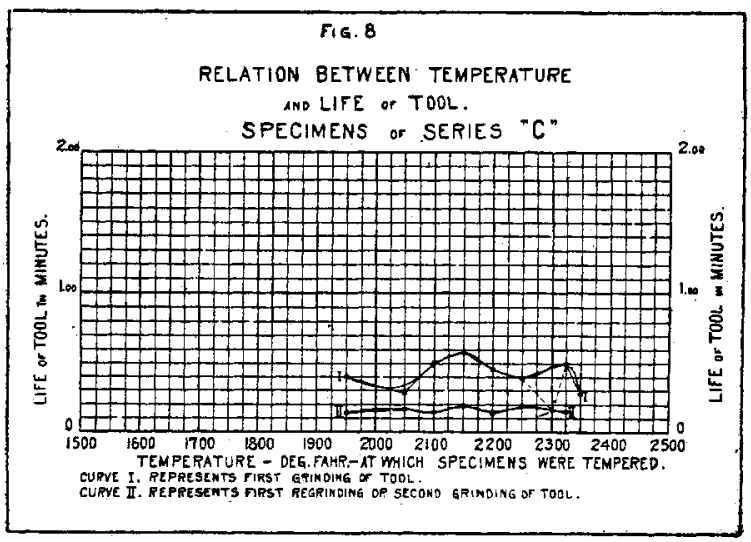

' $C$ " steels-temperature and life.
The cutting speeds were evidently too high for this grade of steel. The durability being very low at all points, the variations are not distinct. However, it will be seen that the durability attains its maximum at $2150^{\circ} \mathrm{F}$. in Curve $\mathrm{I}$, representing the first grinding of the tool. The dotted lines show that the specimen which was quenched at $2300^{\circ} \mathrm{F}$. failed and broke almost immediately after starting.

Curve II, representing the second grinding of the tool, does not show any variations whatever, and the difference between this and first grinding is negative. Both these occurrences are directly due to an increase in cutting speed of 20 feet per minute for the specimens on second grinding.

The cutting speed, 80 feet per minute for first grinding, and Ioo feet per minute for second grinding, the thickness of shaving or feed per revolution, 0.0339 inch, and depth of cut, $1 / 4$ inch at each end of the tool, were kept constant for all specimens.

Results from the tests run on the specimens of Series $D$ are shown by the diagram in Fig. 9. In this

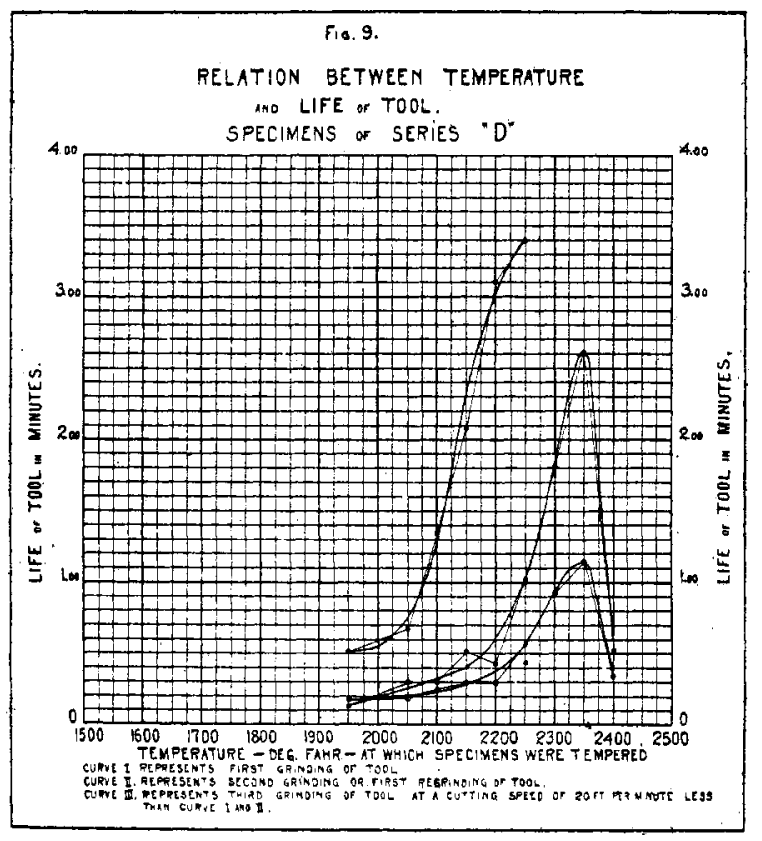

"D" steels-temperature and life.

diagram it may be noted that part of the specimens were subjected to a test also after being ground a third time.

All three curves (I, II, and III) show the variations very distinctly, and of exceptionally high durability, with the attained maximum at the quenching temperature of $2350^{\circ} \mathrm{F}$. for both the first and the second grinding.

The specimen quenched at $2400^{\circ} \mathrm{F}$. broke on the second grinding after failing in the length of time (0.52 minute) as shown in the diagram.

Only part of the specimens were run on the third grinding, simply for the reason that the time for 
- boring one cylinder would not be sufficient for the tool to fail at a cutting speed of 80 feet per minute. Cutting on more than one cylinder with the same tool would cool the cutting edge of the tool while changing and the result could not be considered.

The cutting speed, roo feet per minute for first and second grinding, and 80 feet per minute for third grinding, the thickness of shaving or feed per revolution, 0.0339 inch, and the depth of cut, $1 / 4$ inch at each end of the tool, were kept constant for all specimens.

In Fig. Io is shown a diagram giving by percentage the relation between temperature and life of tool, of

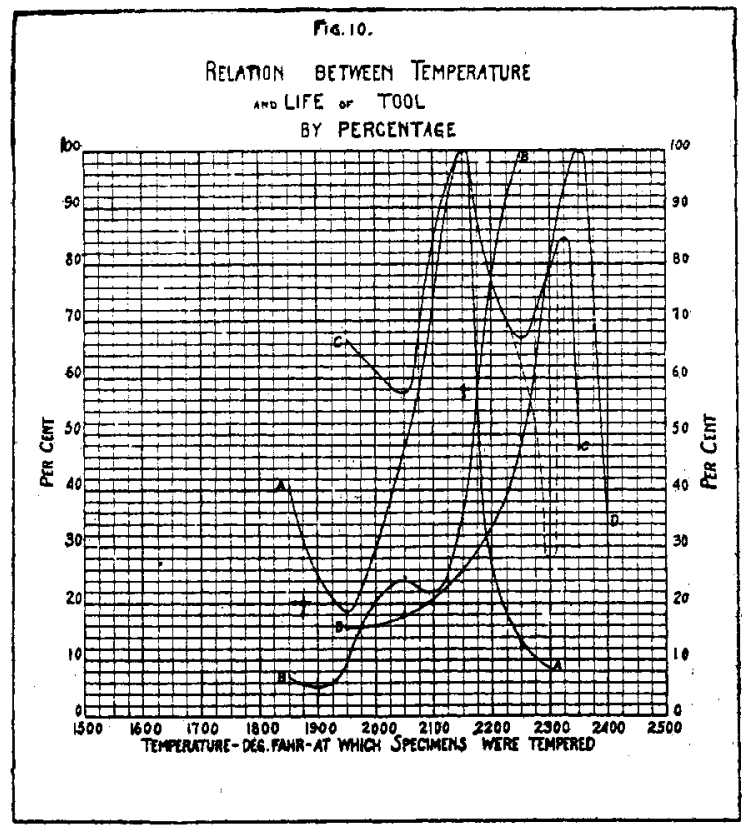

The varying life of tools from tempciatures.

the four series of specimens. The temperature forms the base of the diagram, and the ordinate is made into a per cent. scale.

The maximum life or durability of the tool is taken as the unit or put at Ioo per cent., and the durability in percentage of the maximum can be read from the curves for any temperature used.

Metallurgical Examination by Photomicrographs.In examining the photographs of the specimens from Series A, it can be seen that the size of the grain increases with the temperature at which the specimen was quenched.

Specimen No. 7 , because of its size of grain, absolute freedom from separation of the constituents of the steel, and the absence of the physical defects, which appear in the specimens preceding and following this one, is the one which will be able to best withstand the vibration and rough treatment of highspeed cutting.

In specimen No. o the hard constituents can be seen to have separated out, forming a network around the steel crystals.
The crystals of the steel under work are forced to move around, rubbing against each other like a ball and socket joint, and this hard constituent surrounding the crystals acts in the same manner as emery in a ball and socket joint, increasing the friction and generating heat, which will rapidly destroy the tool. This specimen also shows by its physical defects and back structure (decarburized steel) that the steel was burned.

The illustrations from full-size photographs of fractures from the specimens in this series also indicate clearly the increasing size of grain with the quenching temperature of the specimen.

Examining the illustrations of the specimens from Series B, it will be seen that the grain of the steel increases gradually up to specimen No. I6, and afterwards very rapidly, showing that the steel is very sensitive to heat treatment above the temperature at which this specimen was treated.

For the same reason that specimen No. 7 was chosen as the best of Series A, specimen No. 16 is selected of this group. The physical defects which appear in the specimens preceding and following specimen No. 16 are entirely absent here.

Comparing this result with the results of the physical test shown in the diagram (Fig. 7) it appears that the two do not dgree for this steel. The diagram shows the maximum durability of the Series B is attained by specimen No. 19. This occurrence can hardly be accounted for unless it is due to a minimum of separated hard constituents around the steel crystals, even at the higher temperatures.

The illustrations from full-size photographs of the fracture show the increasing grain with the quenching temperature like the steel in Series A.

The illustrations of the specimens of Series $C$ show that the size of crystal grains in this group increase gradually up to the point where the steel becomes burned, as shown in specimen No. 30 .

For the series No. 24 is chosen as the best specimen, because of its clean structure, the absence of any separation of the constituents, and the uniform size of the crystal grains.

In specimen No. 30 the steel shows the same effects of burning as specimen No. o of Series A, the separation of hard constituents around the crystals and the black decarburized spots.

Also in this series the illustrations from full-size photographs of fractures show the increase in size of grain with the temperature.

The illustrations of the specimens of Series D show a very uniform structure up to specimens No. 38 and 40 .

Specimen No. 40 shows distinctly marks of being burned, by the black decarburized spots, but the hard constituents surrounding the crystals, which are found in other burned specimens, are entirely absent here. 
Fractures from specimens of Series A

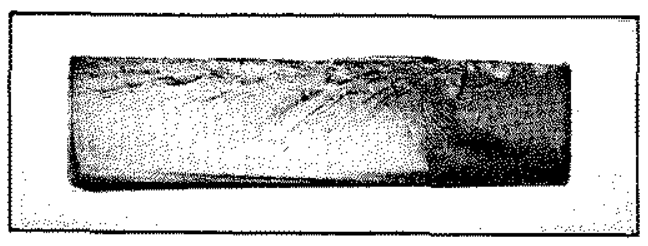

1- Quenched at $1850^{\circ}$ Fahr

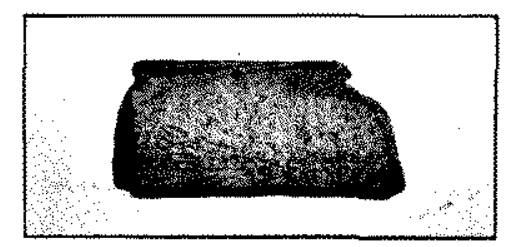

3-Quencized at $1950^{\circ}$ Fahr.

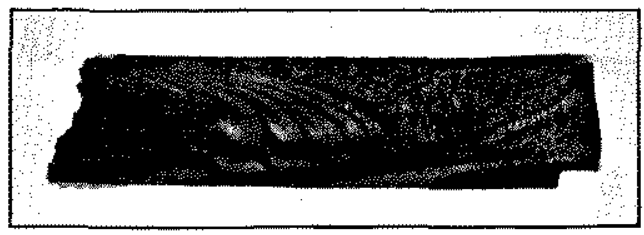

5-Quenched at $2050^{\circ}$ Fahr.

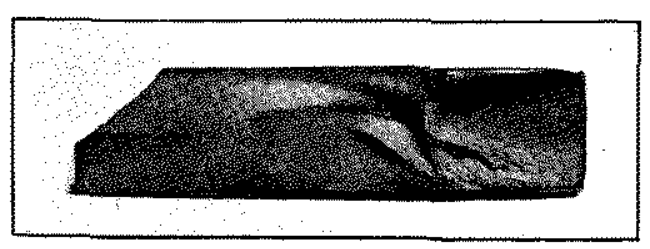

7 -Quencied at $2150^{\circ}$ Fahr.

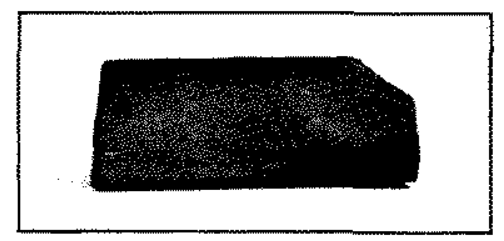

$9-$ Quenched at $2250^{\circ}$ Fiahr.

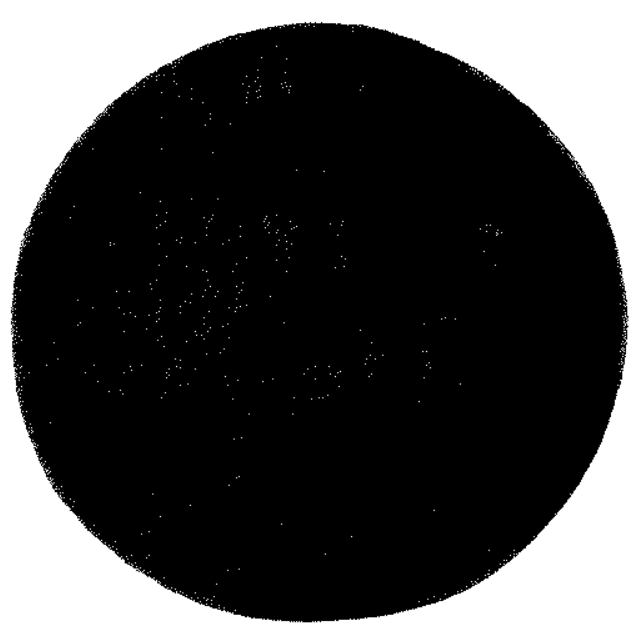

No. 1 .

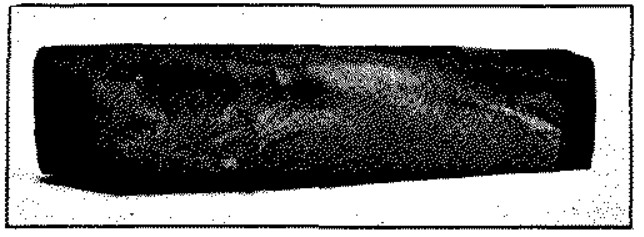

2-Quenched at $1900^{\circ}$ Fahr.

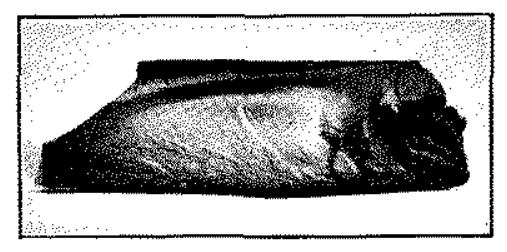

4-Quenched at $2000^{\circ}$ Fahr.

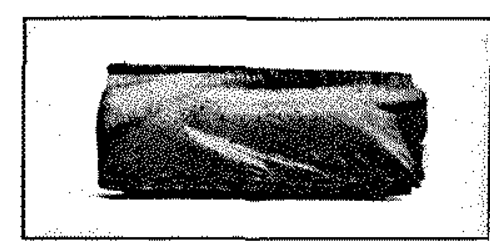

6-Quenched at $2100^{\circ}$ Fahr.

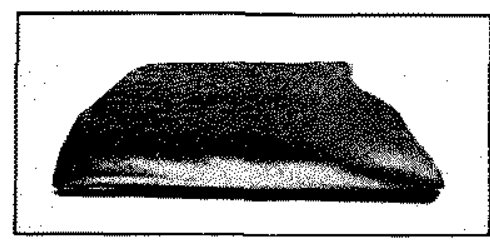

8-Quenched at $2200^{\circ}$ Fahr.

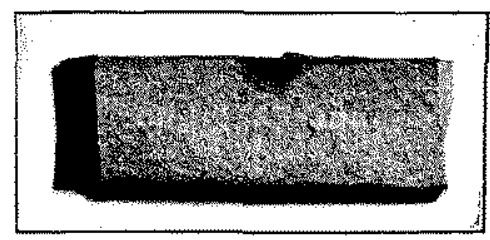

$10-$ Quenched at $2250^{\circ} \mathrm{Fahr}$

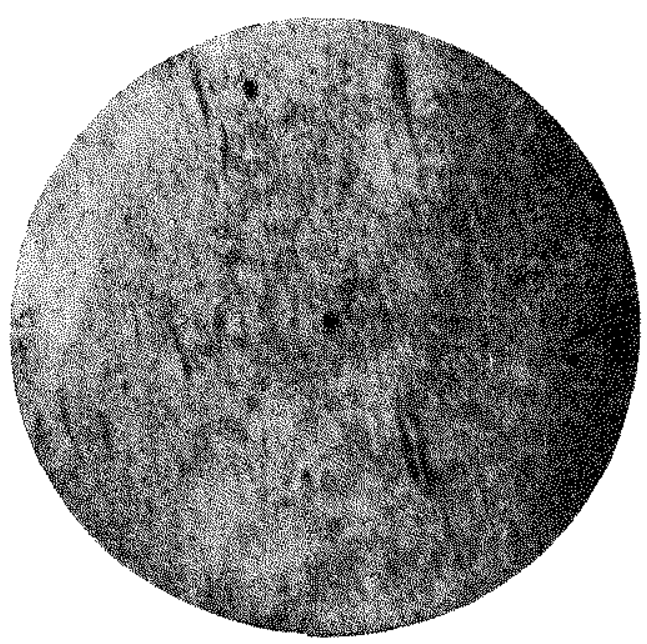

No. 4. 

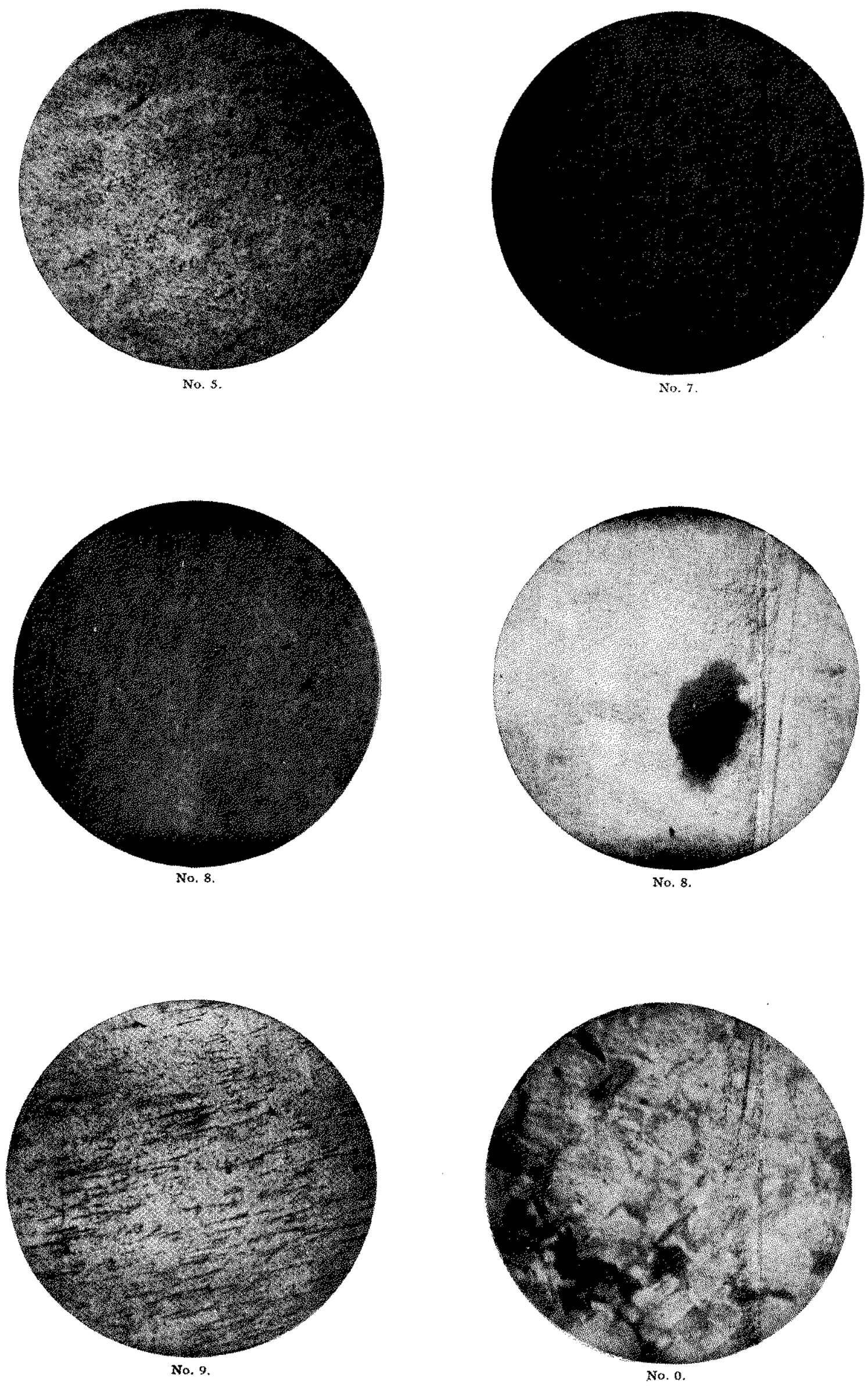
Fractures of Specimens. Series B.

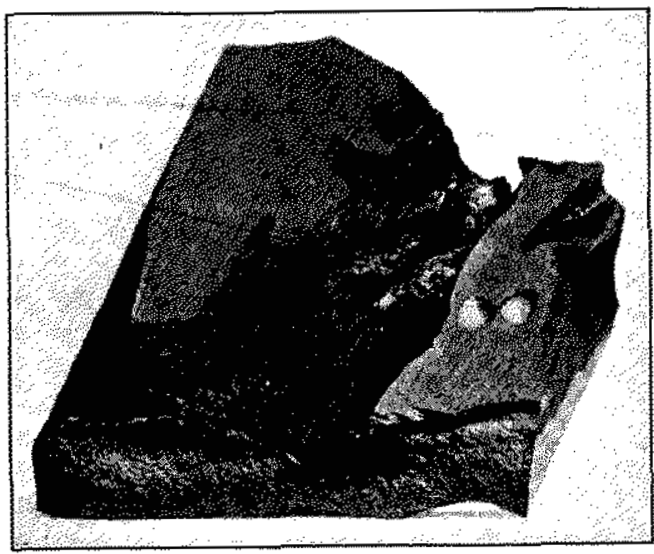

Series A. No. 0.

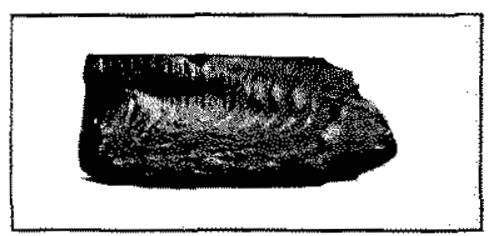

$13-$ Quenched at $1950^{\circ}$ Fahr.

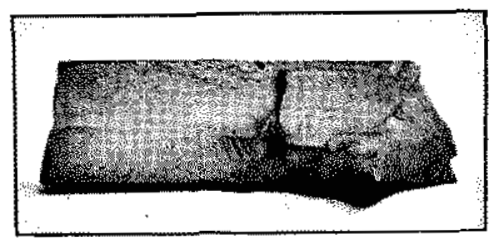

15-Quenched at $2050^{\circ}$ Fahr.

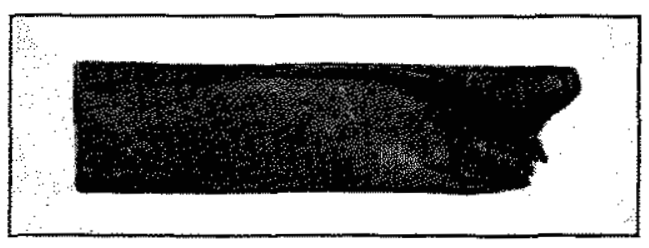

17-Quenclied at $2150^{\circ}$ Fahr.

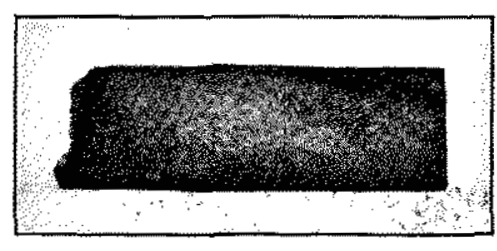

19-Quenched at $2250^{\circ} \mathrm{Fahr}$.

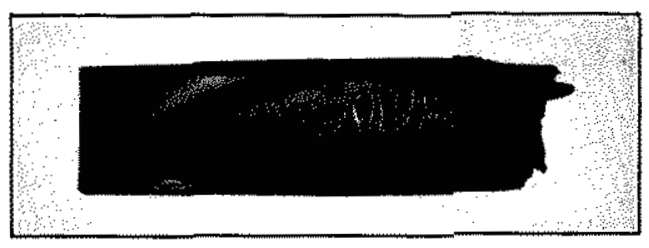

1I-Quenched at $1850^{\circ}$ Faht.

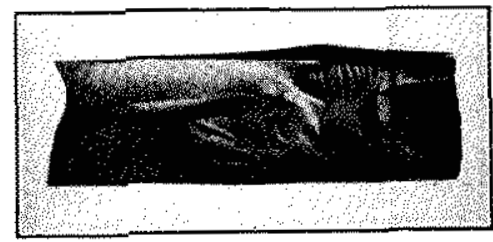

$12-$ Quenclied at $1900^{\circ}$ Falur.

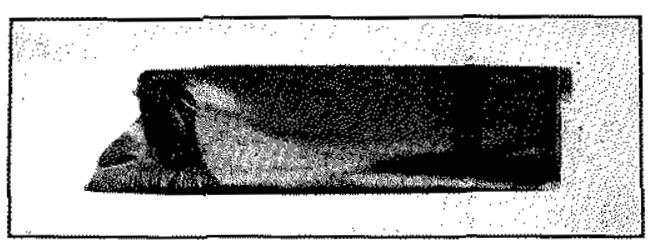

14- Quenched at $2000^{\circ}$ Fahr.

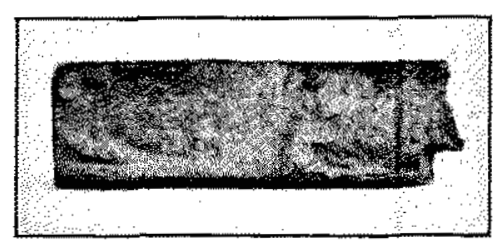

16 -Quenched at $2100^{\circ}$ Fialu.

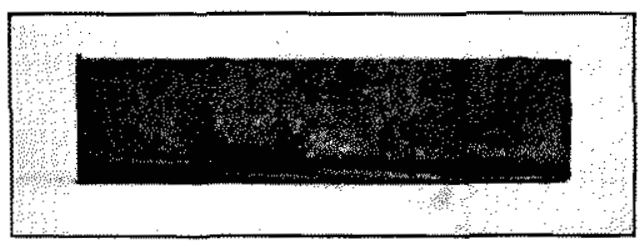

18 -Quenched at $2200^{\circ}$ Fahr.

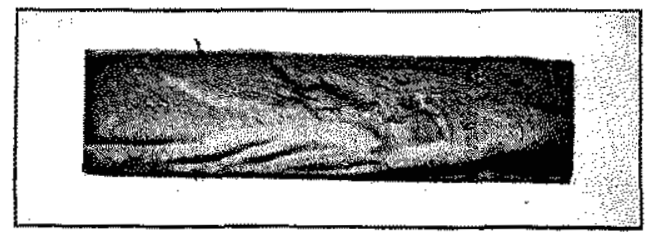

20 -Quenched at $1750^{\circ}$ Fahr. 

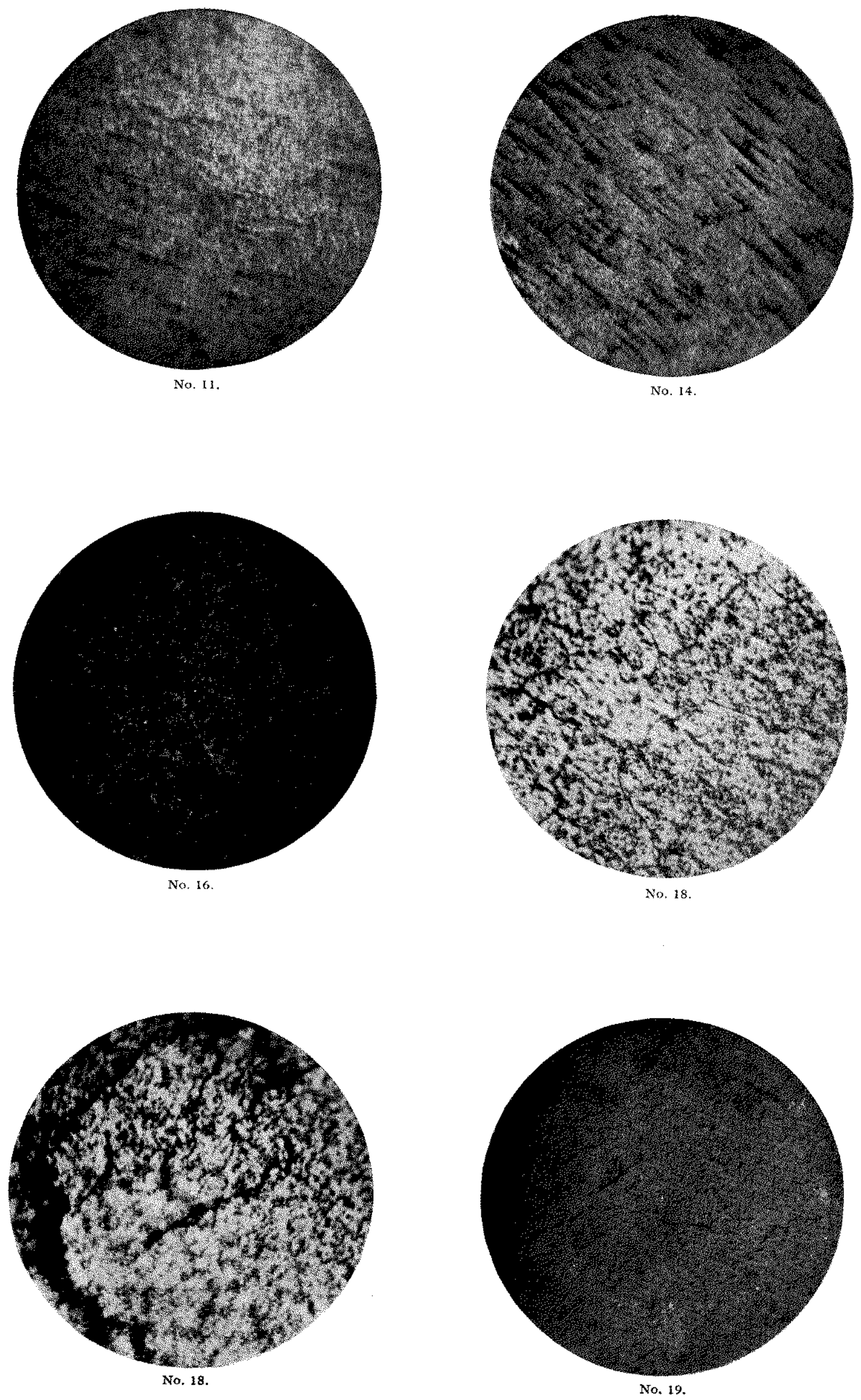
Fractures of specimens. Serics C.

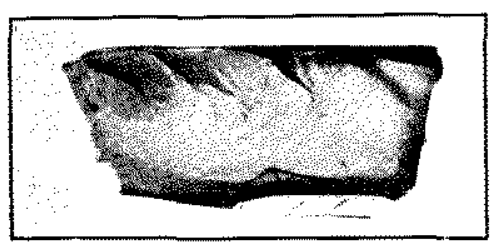

21 -Quenched at $19.90^{\circ}$ Fallo

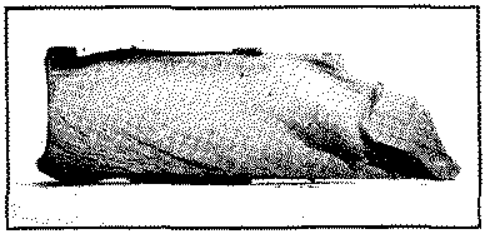

23-Quenched at $2100^{\circ}$ Falur

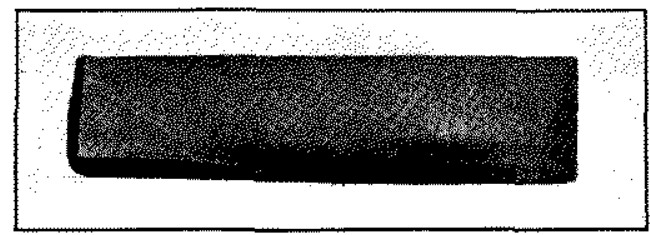

25-Quenched at $2200^{\circ}$ Falı.

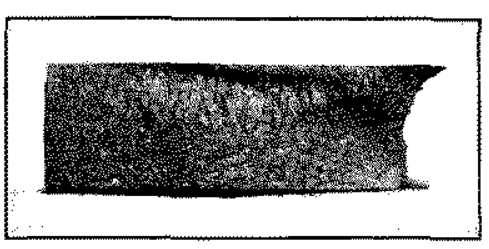

27 -Quenched at $2300^{\circ}$ Frahr.

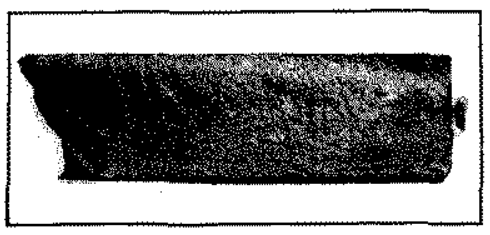

29 -Quenched at $2325^{\circ}$ Fialsr.

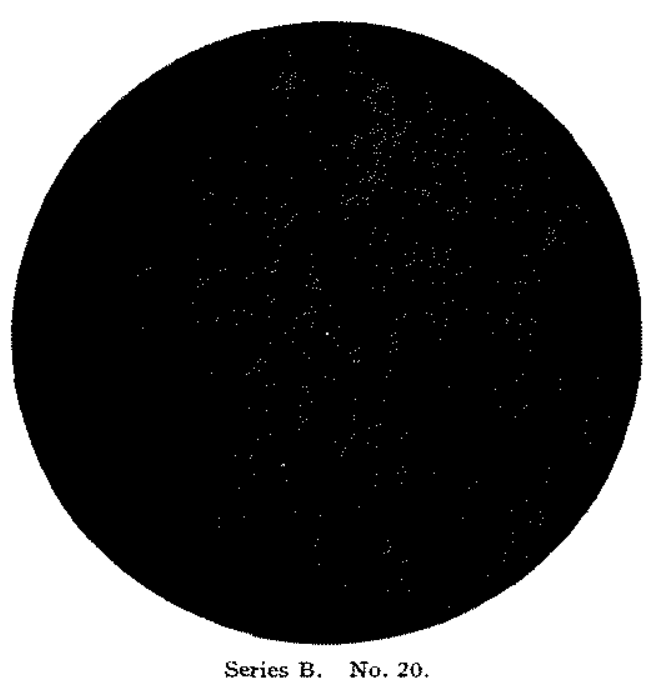

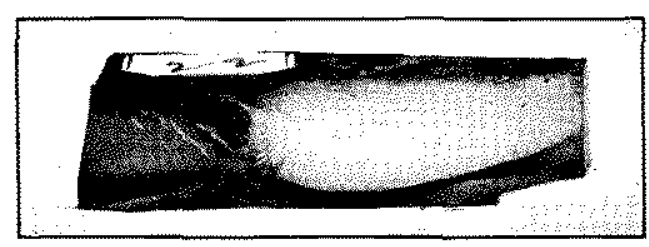

22 Quenched at $2050^{\circ}$ fathr.

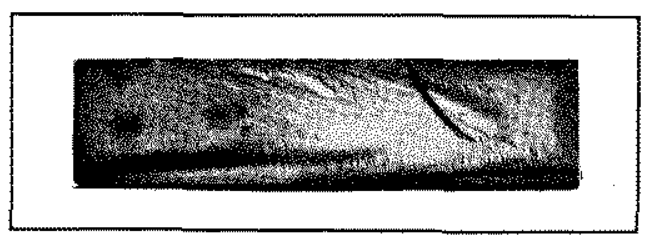

24-Quenched at $2150^{\circ}$ Fahr.

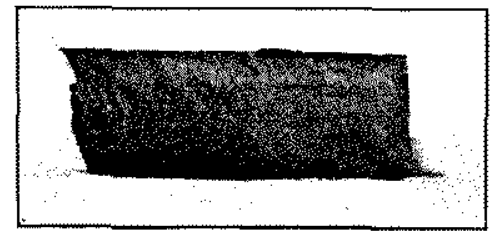

26-Quenched at $2250^{\circ}$ Fahr

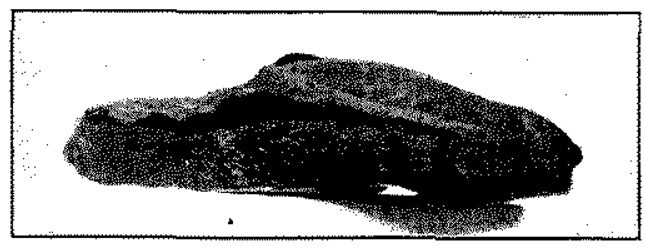

28 -Quenched at $2359^{\circ} \mathrm{Fahr}$.

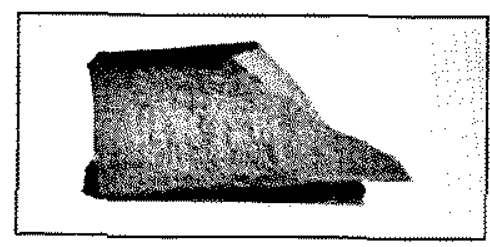

30-Quenched at $2350^{\circ}$ Fahr.

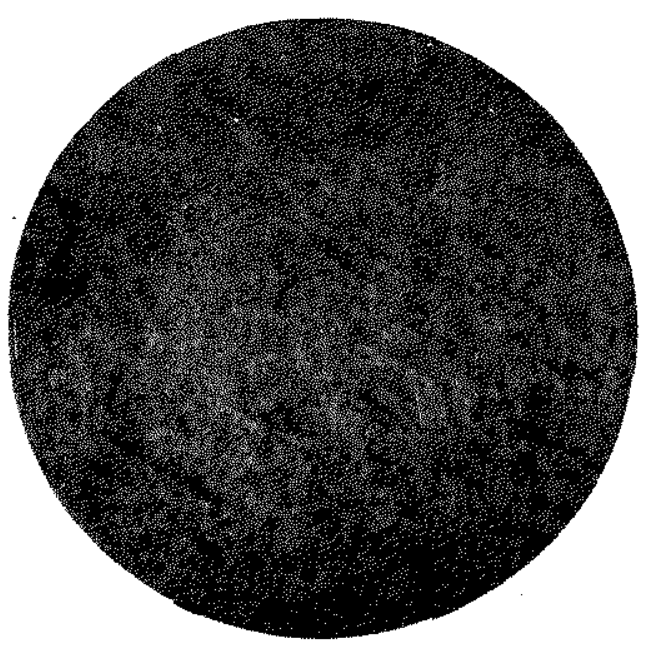

No. 21. 

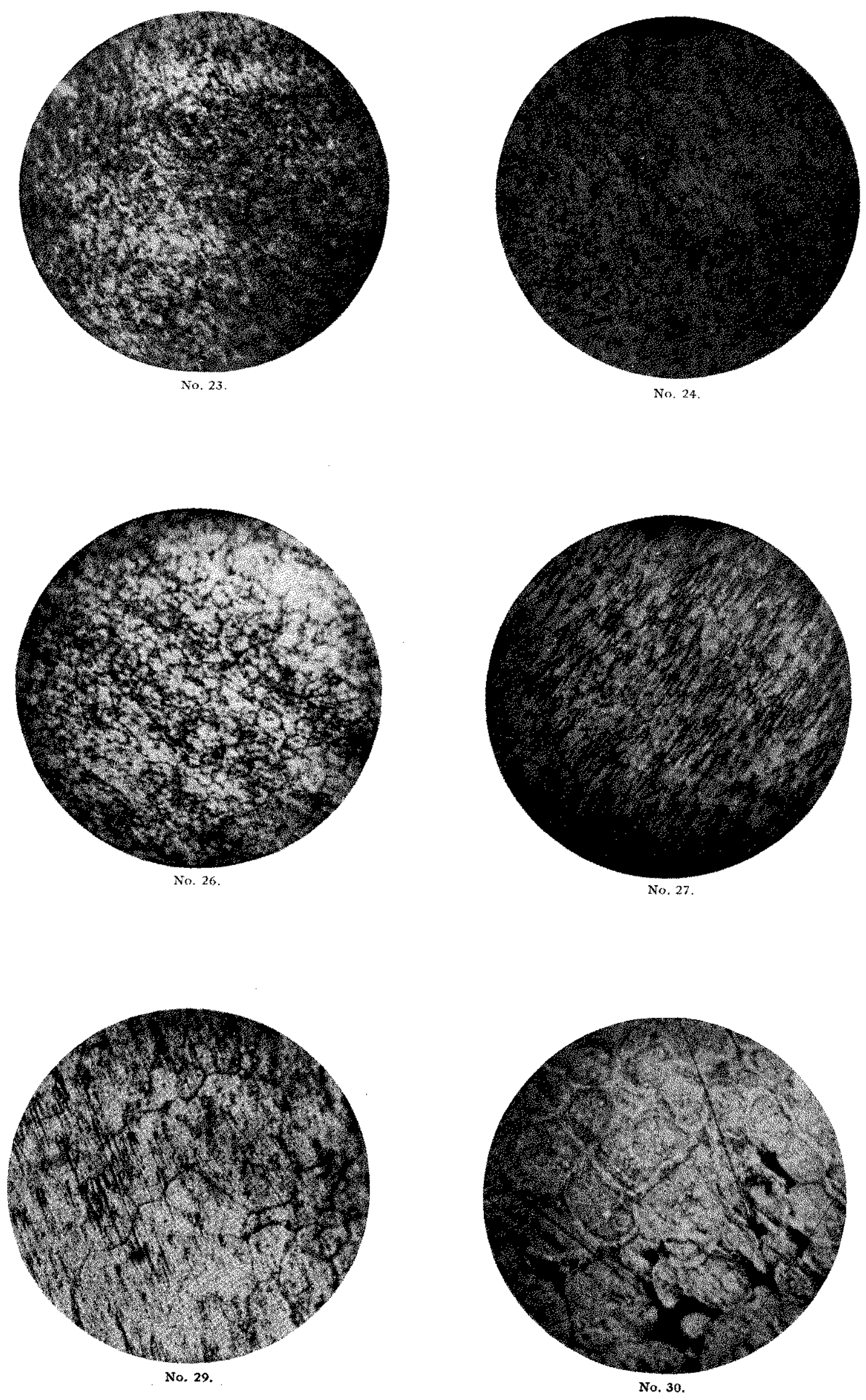


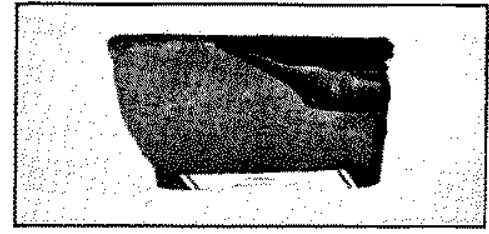

31-Quenched at $1950^{\circ}$ Falh.

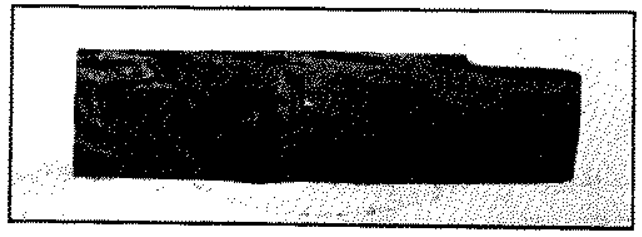

$33-$ Quencined at $2100^{\circ} \mathrm{Fahr}$

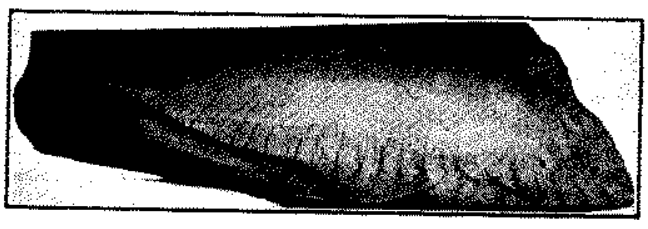

35 -Quenched at $2200^{\circ}$ Fahr.

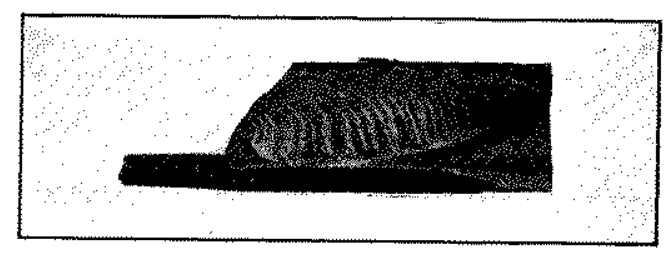

37 -Quenched at $2300^{\circ}$ Fahr.

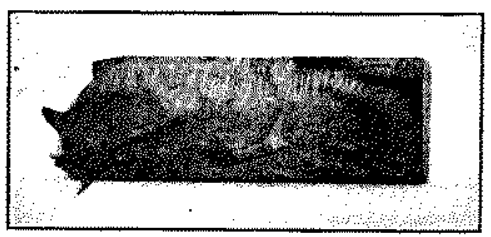

$39-$ Quenched at $2300^{\circ}$ Yrahr.

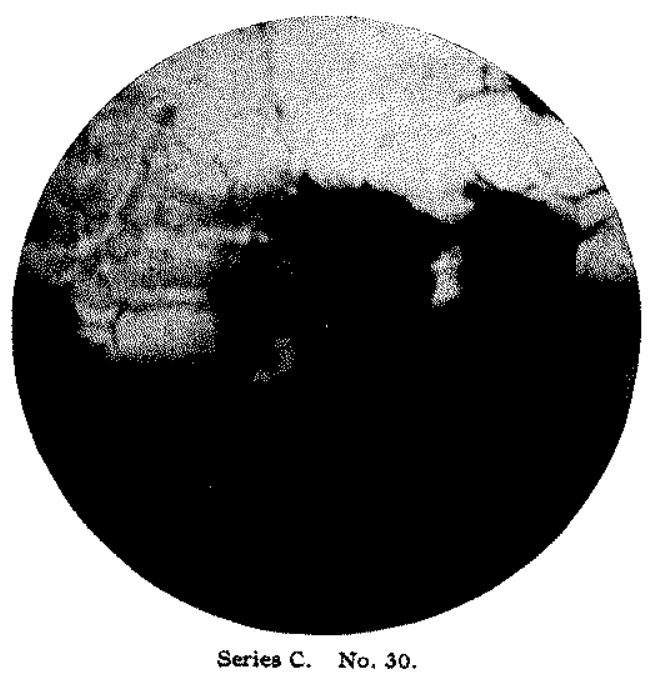

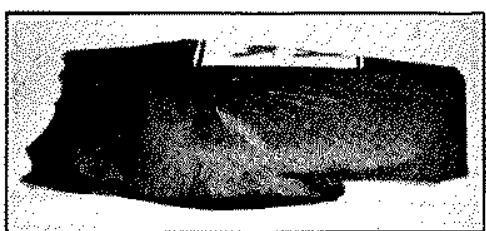

$32-$ Quenched at $2050^{\circ}$ Fahr.

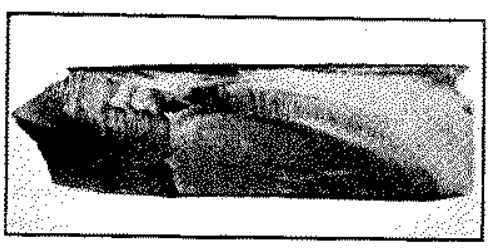

34-Quenched at $2150^{\circ}$ Falur

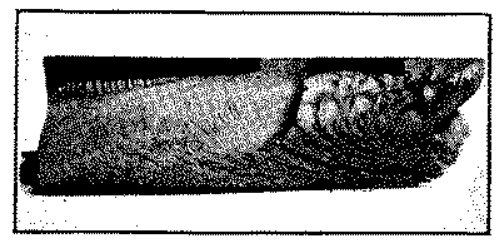

36-Quenched at $2250^{\circ} \mathrm{Fahr}$

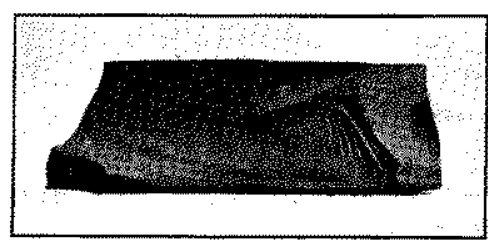

38 -Quenched at $2350^{\circ}$ Fahr.

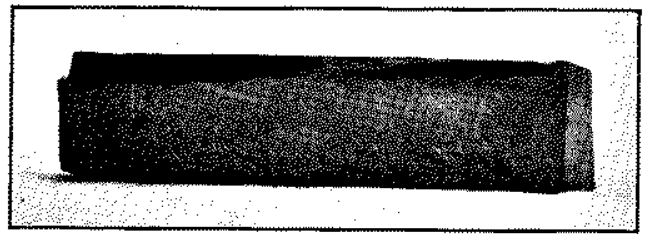

40-Quenched at $2400^{\circ}$ Fahr.

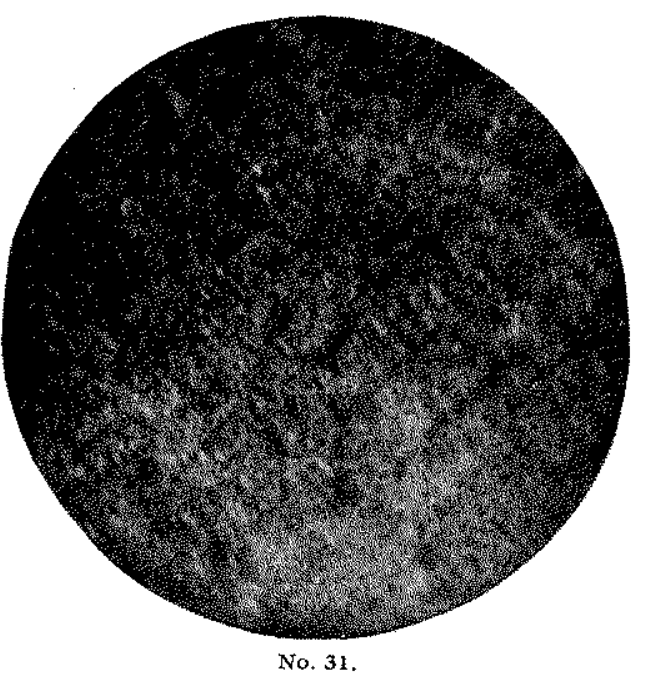



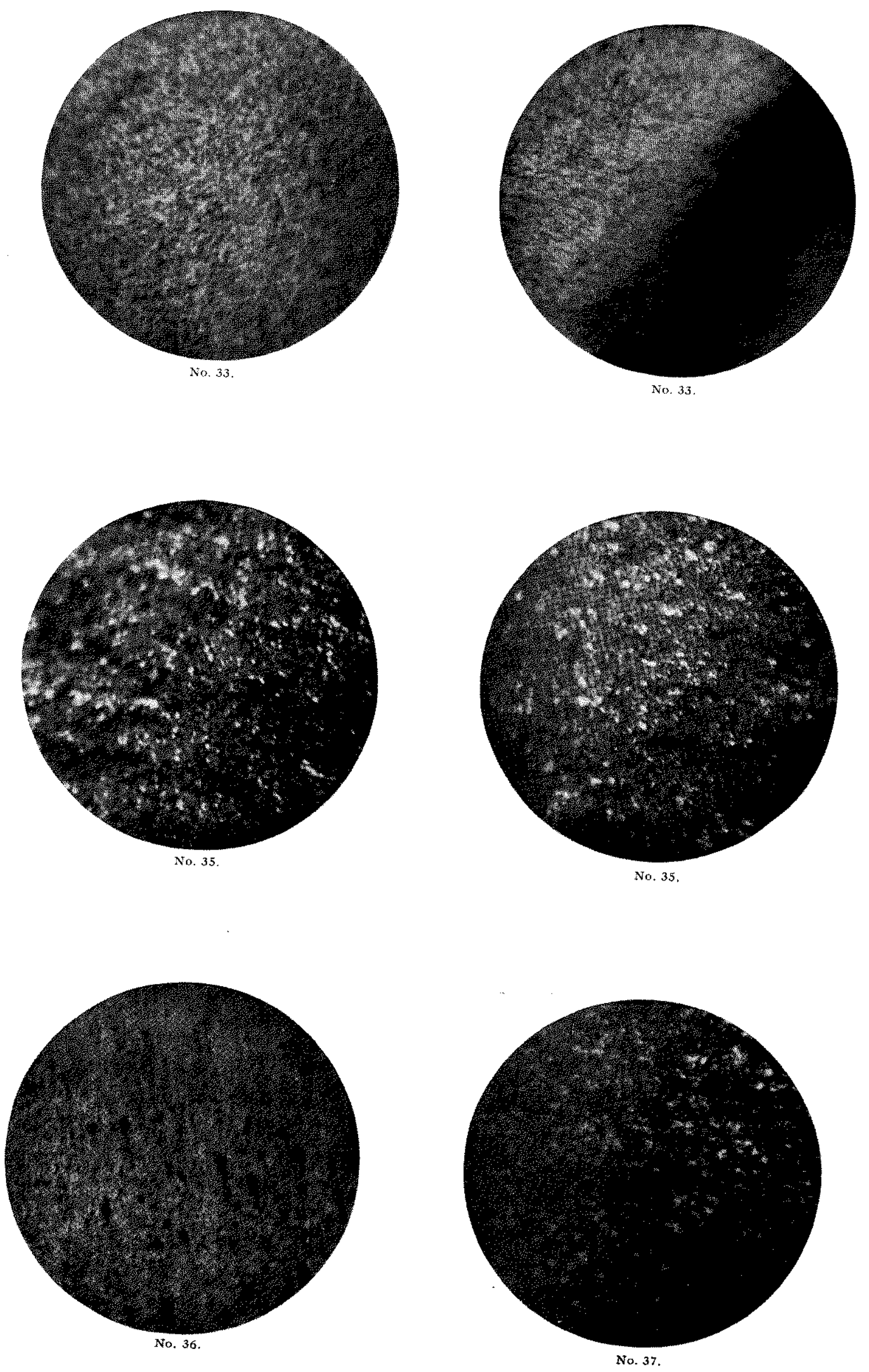
Specimen No. 38 shows a distinct difference from the ones just preceding and following, indicating that this steel has a narrow range of temperature in which it can be treated with the best results. This specimen shows the clearest and cleanest structure and is microscopically the best specimen of the group.

In the reproduction of one of the photographs from specimen No. 33 is shown a case referred to in paragraph No. 24. It illustrates the cracking of a specimen which has been heated too rapidly, and quenched before the heat had been allowed to uniformly penetrate to the center of it. However, it does appear remarkable that this specimen did not break under the physical test.

The illustrations from photographs of the fractures show the increase in size of grain as in the preceding series.

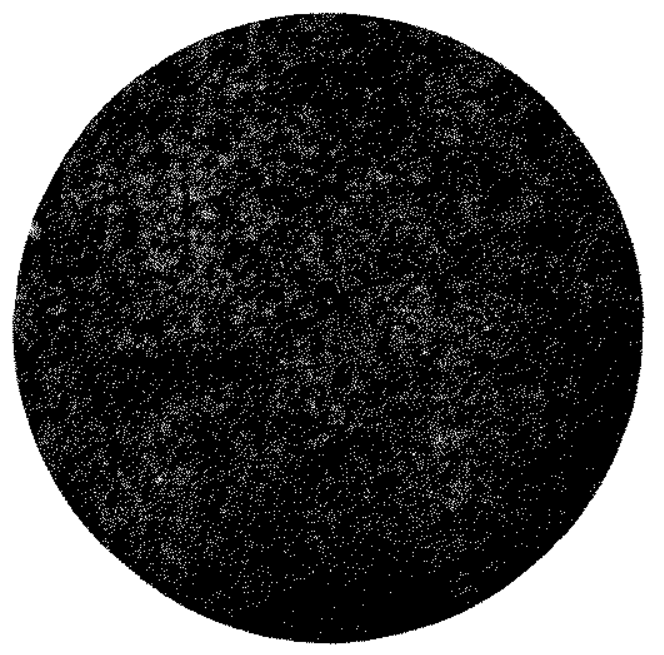

No. 38 .

Red Hardness as Affected by the Structure of the Steel. - The property named red hardness in a highspeed tool steel, and which enables it to cut metal when the cutting edge and near portions are heated to a dull red, should, to a certain extent, be related to the structure of the steel according to the above statements.

The heat which is generated by friction between the steel crystals (these being caused to move by vibration) does not destroy the tool as rapidly as the grinding on the crystals by the separated hard constituents, which are present at some temperatures. As the structure of the steel in this case generally consists of crystals of an uneven size, the smaller ones of these are ground to pieces in a comparatively short time, and the cutting edge of the tool is ruined.

Therefore, a uniform size of crystals without separated hard constituents between them in the structure of the tool steel will give a large amount of red hardness or high durability, considering the structure of the steel only and apart from the various effects of the chip upon the tool in cutting metals.
To find the element, or combination of elements, in the steel responsible for the highest durability, requires the most elaborate experimenting, in the making of the steel, the heat treatments, and the physical tests, and is beyond the object of the experiments described in this paper. However, it is seen that two slightly different chemical compositions of the steel, subjected to the same heat treatment, show a great difference in durability.

Taking the results of these experiments as a whole, the general shop rule for treating a high-speed tool"Heat it to a white heat and quench it"- does have its shortcomings, because a variation of $50^{\circ} \mathrm{F}$. cannot be determined by the eye.

What are the results of a poorly treated tool? It decreases the shop production for the manufacturer, who allows it inside his establishment.

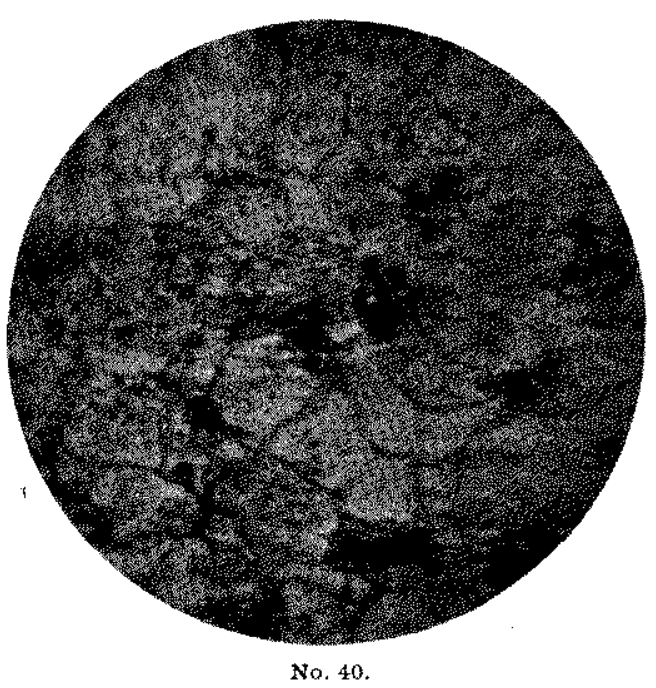

It increases the bill of the customer, wlo pays for the tool and the work spent on it.

When the works manager comes through the shop and inquires about the tools, the workman naturally testifies the tool steel to be of inferior quality, which, as we have seen, may not be the case, but this tool steel maker has to find a new market for his stock of steel.

In short, it is waste of energy and waste of capital.

\section{APPLICATION OF ELECTROSTATIC SEPARATION TO ORE DRESSING.}

By F. S. MacGregor.

The possibility of utilizing the differences in the electrical conductivity of various minerals by giving a part or all of the particles of ore an electrostatic charge has for several years been recognized as a means of separation, and a large amount of experimenting has been done along this line. The com-

1 A paper presented at the Eighteenth General Meeting of the Axnerican Electrochemical Society, in Chicago, October 13-15, 1910 , 